\title{
Environmental Factors Affecting the Formation of Mesityloxide, Dimethylallylic Alcohol and Other Volatile Compounds Excreted by Anabaena cylindrica
}

\author{
By FRIEDRICH JÜTTNER,* JUTTA LEONHARDT AND \\ SABINE MÖHREN \\ Institut für Chemische Pflanzenphysiologie der Universität, D-74 Tübingen, \\ Federal Republic of Germany
}

(Received 20 May 1982; revised 2 August 1982)

\begin{abstract}
Anabaena cylindrica excretes a large number of volatile products. The major components are dimethylallylic alcohol and mesityloxide, while the minor components detected include various nor-carotenoids and lipid degradation products. The formation of mesityloxide is strictly lightdependent, and ceases in the dark. A direct association with photosynthesis can be ruled out since 3-(3,4-dichlorophenyl)-1,1-dimethylurea (DCMU) does not affect the formation of mesityloxide during the first hour after application, but immediately inhibits the evolution of oxygen.
\end{abstract}

\section{INTRODUCTION}

Cyanobacteria contain a broad spectrum of different carotenoids, some resembling those of the green algae, others being unique to this group of organisms (Stransky \& Hager, 1970; Hertsberg et al., 1971). Apart from these tetraterpenoids, very few smaller terpenoids have been detected in cyanobacteria. Initially, steroids were stated to be absent from cyanobacteria (Levin \& Bloch, 1964), but later work has characterized a small number of these compounds (Reitz \& Hamilton, 1968; Nadal, 1971). Reports on regular di-, sesqui- and monoterpenes are still lacking. However, irregular mono- and sesquiterpenes have been detected. $\beta$-Cyclocitral is the major excretion product of Microcystis (Jüttner, 1981a), and its carbon skeleton indicates biosynthesis of this monoterpene from carotenes by oxidative cleavage. Other components described are 2-methylisoborneol, a bicyclic $\mathrm{C}_{11}$ compound, and geosmin, a $\mathrm{C}_{12}$ terpene alcohol (Gerber, 1968). As far as is known, the latter are liberated exclusively by filamentous cyanobacteria (Safferman et al., 1967; Kikuchi et al., 1973; Tabachek \& Yurkowski, 1976). Though biosynthetic studies have not been conducted, a subsequent introduction of a methyl group and loss of an alkyl group, respectively, is evident for these two substances. Their strong muddy odour together with their extremely low odour thresholds (Persson, 1980) gives rise to serious problems in fisheries and in the production of drinking water. A significant correlation between the number of Oscillatoria agardhii present in the phytoplankton and off-flavours in bream has been demonstrated (Persson, 1979). The results of a survey on North American water supplies (Sigworth, 1957) indicated that odour problems are most frequently caused by diatoms of the genera Asterionella and Synedra, followed by Anabaena species and other cyanobacteria.

During the course of studies on volatile excretion products of cyanobacteria and algae we have found two terpenoid substances which were identified as mesityloxide and dimethylallylic alcohol and which were excreted in exceptionally high amounts by the well-studied species Anabaena cylindrica.

Abbreviation: DCMU, 3-(3,4-dichlorophenyl)-1,1-dimethylurea. 


\section{METHODS}

Organism. Anabaena cylindrica, identical to strain 1403/2a, Culture Centre of Algae and Protozoa, Cambridge, U.K., was obtained from Dr N. G. Carr, Department of Biochemistry, Liverpool, U.K.

Culture medium and conditions. The cyanobacteria were cultivated in $300 \mathrm{ml}$ culturing tubes at $27^{\circ} \mathrm{C}$, gassed with a $0.27 \%(v / v) \mathrm{CO}_{2} /$ air mixture from below and illuminated with one fluorescent tube (1000 lx $)$. After each transfer, the axenic nature of the cultures was tested by streaking samples on nutrient agar plates (DEV-nutrient agar, Merck no. 11471). The medium used contained : $0.6 \mathrm{~mm}-\mathrm{CaCl}_{2}, 8 \mathrm{~mm}-\mathrm{NaNO}_{3}, 0.4 \mathrm{~mm}-\mathrm{K}_{2} \mathrm{HPO}_{4}, 0.4 \mathrm{mM}-\mathrm{MgSO}_{4}$, $10 \mu \mathrm{M}-\mathrm{NaFeEDTA}$ (from Fluka, Neu-Ulm, Germany), $10 \mu \mathrm{M}-\mathrm{H}_{3} \mathrm{BO}_{3}, 10 \mu \mathrm{M}-\mathrm{MnCl}_{2}, 2 \mu \mathrm{M}-\mathrm{Na}_{2} \mathrm{MoO}_{4}, 0 \cdot 2 \mu \mathrm{M}-$ $\mathrm{ZnSO}_{4}, 0 \cdot 2 \mu \mathrm{M}-\mathrm{CuSO}_{4}$ and $0 \cdot 2 \mu \mathrm{M}-\mathrm{CoSO}_{4}$, in distilled water.

Determination of chlorophyll a and protein. The cyanobacteria were extracted with ethanol and chlorophyll $a$ was determined by using the absorption coefficient given by Seely \& Jensen (1965). The protein content of the extracted residue was determined with a biuret reaction using bovine serum albumin as a standard.

Identification of the volatile substances. The volatile components of $100 \mathrm{ml}$ of $A$. cylindrica suspension in the declining exponential growth stage were stripped after addition of $20 \mathrm{~g} \mathrm{NaCl}$ in a closed loop system, adsorbed on an odour trap, then thermally transferred into a gas chromatograph and separated on a glass capillary column as described previously (Jüttner \& Wurster, 1979; Jüttner \& Hahne, 1981).

Reference compounds and chemicals. Chemicals and reference compounds were either purchased or synthesized as stated previously (Jüttner, 1981 b). 6-Methylhept-5-en-2-ol was synthesized from 6-methylhept-5-en-2-one which was a kind gift of the BASF/Ludwigshafen/Germany. The alcohol was obtained in high yield after reduction with $\mathrm{NaBH}_{4}$ in acetonitrile/water.

Quantitative determination of the volatile components in fermenter cultures. The quantitative determination of the volatile components in fermenter cultures was performed as described by Jüttner \& Hahne (1981). The medium used here was supplemented with $20 \mathrm{mM}-\mathrm{NaHCO}_{3}$. At the beginning of the experiment, aeration was stopped and $20 \mathrm{ml}$ samples were withdrawn for the determination of the volatile components.

Quantitative determination of the growth-dependent formation of the volatile components. Samples $(200 \mathrm{ml})$ of suspension of $A$. cylindrica in the exponential growth stage were diluted with $1000 \mathrm{ml}$ of fresh medium, divided into twelve $300 \mathrm{ml}$ Erlenmeyer flasks closed with aluminum foil and incubated in an incubation shaker $\left[27^{\circ} \mathrm{C}, 110\right.$ strokes $\mathrm{min}^{-1}, 1400 \mathrm{~lx}$, gassing at $500 \mathrm{ml} \mathrm{min}^{-1}$ with $0 \cdot 27 \%(\mathrm{v} / \mathrm{v}) \mathrm{CO}_{2}$ in air]. At one-day intervals flasks were withdrawn and the volatile components determined in $20 \mathrm{ml}$ samples as described above.

\section{RESULTS}

Though cultures of Anabaena cylindrica have only a weak odour, the gas chromatogram (Fig. 1) demonstrates the presence of an appreciable number of volatile components which are excreted. The mass fragmentation patterns along with the retention times were used to identify the substances. A compound was regarded as being positively identified when it could not be separated on a glass capillary column spiked with the authentic substance. The nature of peak 18 remains unknown. The mass spectrum exhibited features of a branched ketone but the data available were not sufficient to determine its structure.

Difficulties arose initially in differentiating between pollution products which are always present in distilled water, nutrient salts, stoppers and aeration gas, and the excretion products of the cyanobacteria. The best method for determining the origin of single components was to follow their generation during the growth of a culture. Pollution products were present in either stable or erratic concentrations, while cyanobacterial products showed growth-dependent formation. The concentrations of the volatile excretion products present in $A$. cylindrica cultures during exponential growth, declining exponential growth and the beginning of the stationary phase are presented in Figs 2 and 3. Extremely high concentrations of mesityloxide (4methylpent-3-en-2-one) and dimethylallylic alcohol (3-methylbut-2-en-1-ol) were observed, together representing the bulk of volatile excretion products of $A$. cylindrica. Most of the other components were present in concentrations of at least an order of magnitude lower.

The formation of mesityloxide was found to be light-dependent. In an experiment in which cultures were exposed to alternating light and dark conditions, no significant synthesis of this compound could be observed in the dark (Fig. 4). In order to investigate whether formation of mesityloxide is directly coupled to photosynthesis, DCMU, a specific and effective inhibitor of photosynthesis, was added and the formation of mesityloxide followed. The concentration of DCMU $\left(10^{-6} \mathrm{M}\right)$ applied was sufficient to suppress the oxygen evolution completely; however, for at least one hour after application, mesityloxide production was little affected and declined only later. 


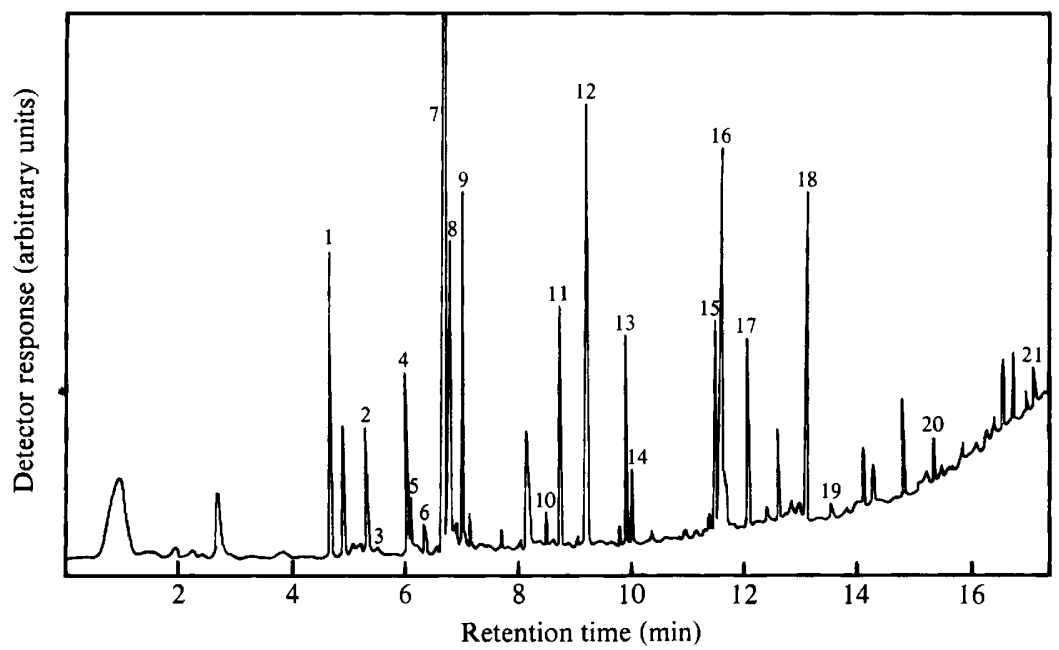

Fig. 1. Volatile compounds isolated from a shaking culture of $A$. cylindrica on the eighth day after inoculation $\left(15 \mu \mathrm{g}\right.$ chlorophyll $a \mathrm{ml}^{-1} ; 130 \mu \mathrm{g}$ protein $\left.\mathrm{ml}^{-1}\right)$ separated on a $25 \mathrm{~m}$ glass capillary column (UCON $50 \mathrm{HB}$ 5100). Pollution products are printed in italics. 1, Penten-3-one; 2, toluene; 3, dimethyldisulphide; 4, cis-pent-2-enal; 5, hexanal; 6, trans-pent-2-enal; 7, mesityloxide; 8, butan-1-ol; 9, pent-1-en-3-ol; 10, pentan-1-ol; 11, cyclohexanone; 12, dimethylallylic alcohol; 13, 6-methylhept-5en-2-one; 14, hexan-1-ol; 15, 6-methylhept-5-en-2-ol; 16, benzaldehyde; 17, 2-ethylhexan-1-ol; 18, ketone (unidentified); 19, $\beta$-cyclocitral; 20, benzyl alcohol; $21, \beta$-ionone.

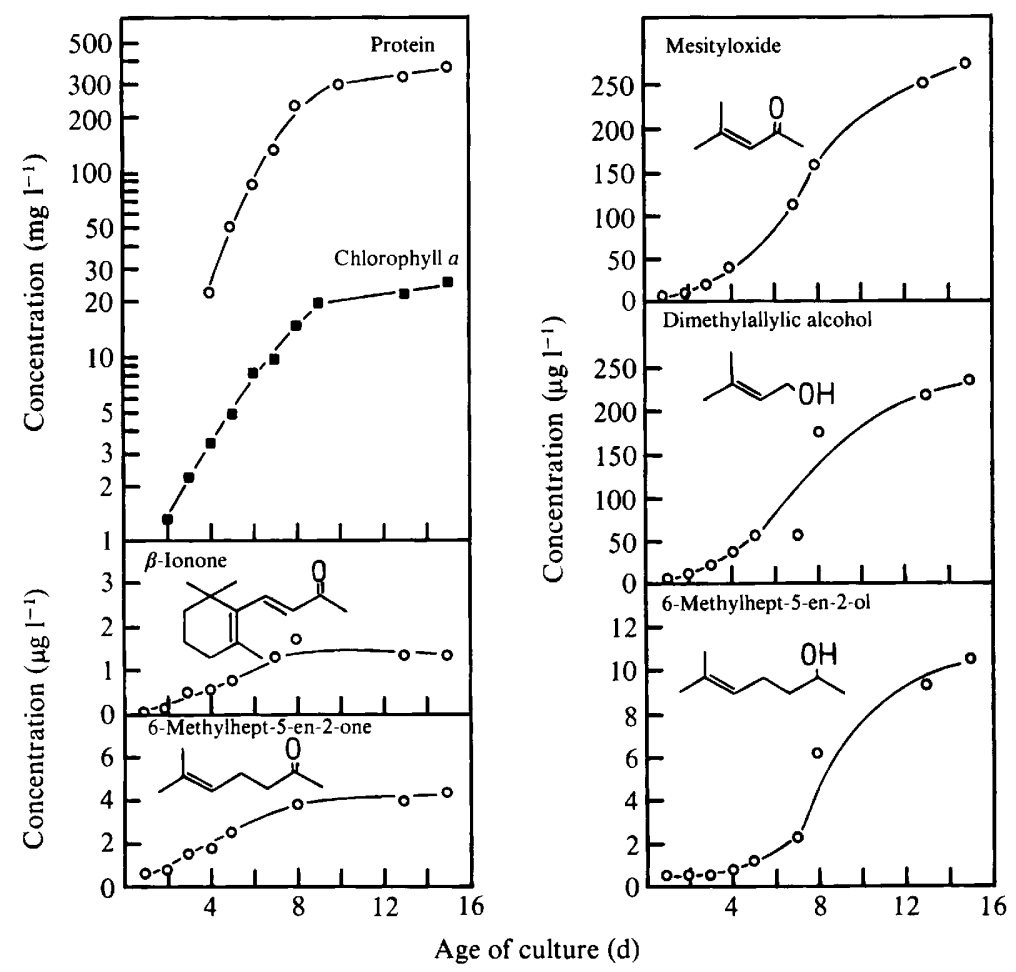

Fig. 2. Time course of growth $(\mathrm{O}$, protein; $\mathbf{a}$, chlorophyll $a)$ and the formation of volatile norcarotenoids ( $\beta$-ionone, 6-methyl-hept-5-en-2-one, mesityloxide, 6-methylhept-5-en-2-ol) and dimethylallylic alcohol in illuminated shaking cultures of $A$. cylindrica. The concentrations of protein and chlorophyll $a$ are in $\mathrm{mg}^{-1}$; those of the other components are in $\mu \mathrm{g} \mathrm{l}^{-1}$. 


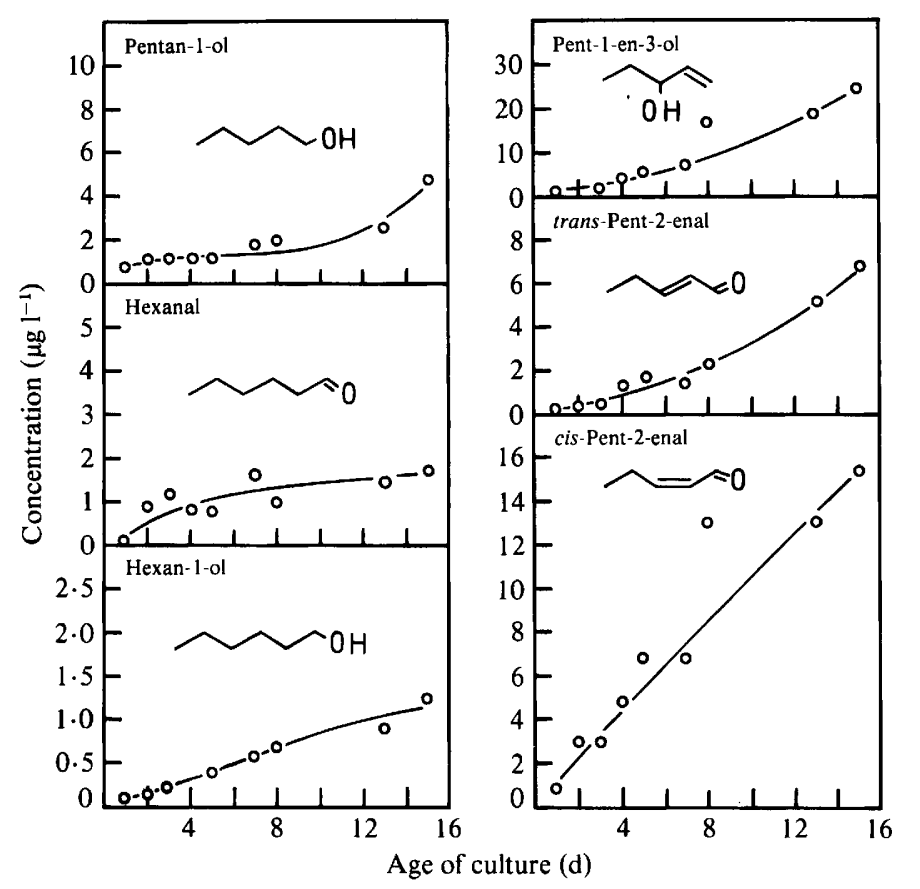

Fig. 3. Time course of the formation of lipid degradation products (pentan-1-ol, pent-1-en-3-ol, hexanal, trans-pent-2-enal, hexan-1-ol and cis-pent-2-enal) of $\boldsymbol{A}$. cylindrica in the same experiment as Fig. 2.

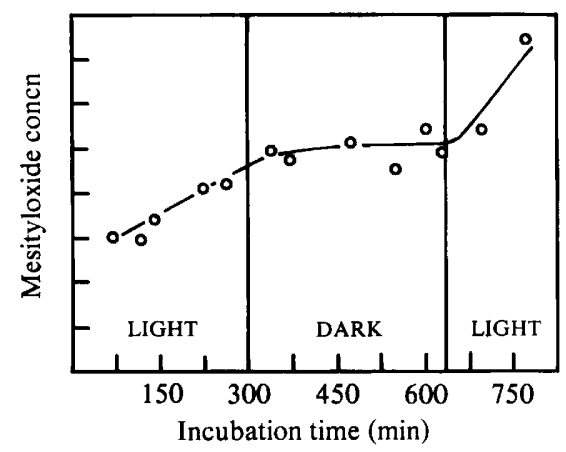

Fig. 4. Concentration of mesityloxide (plotted as the integrated area of the flame ionization detector signal) in a 2 litre fermenter culture of $\boldsymbol{A}$. cylindrica during alternating light and dark conditions.

\section{DISCUSSION}

The volatile substances determined in the medium of Anabaena cylindrica can be divided into two major groups, terpenoid compounds and fatty acid degradation products, according to their presumptive biosynthetic origin. Mesityloxide and 6-methylhept-5-en-2-one belong to the first group and might result from an oxidative cleavage of open-chain carotenes as has been demonstrated in tomatoes (Stevens, 1970). A reduction reaction mediated by an alcohol dehydrogenase could result in the formation of 6-methylhept-5-en-2-ol, which was observed in much higher concentrations than the corresponding ketone. On the other hand, the alcohol corresponding to mesityloxide could not be detected. Nor-carotenoids derived from $\beta$-carotene were represented by $\beta$-cyclocitral and $\beta$-ionone. $\beta$-Cyclocitral has already been detected as the major excretion product of the cyanobacterium Microcystis (Jüttner, 1981a) and $\beta$-ionone and 
6-methylhept-5-en-2-one have been found in the primitive rhodophyte Cyanidium caldarium (Jüttner, 1979). A different biosynthetic pathway involving the action of phosphatase on dimethylallylic pyrophosphate may be responsible for the generation of the extremely high amounts of dimethylallylic alcohol observed. Both major components, mesityloxide and dimethylallylic alcohol, have not been found to constitute major excretion products in any other micro-organism.

The kinetics of formation of the isoprenoid components during different stages of growth were rather similar to one another. High rates were observed during exponential and lateexponential growth and a sharp decline in the stationary growth phase. This agrees with the observation that mesityloxide is synthesized by Anabaena cylindrica exclusively in the light. However, photosynthesis is not directly involved in its formation, as indicated by the small effect of DCMU. Indeed, cessation of its production may be due to depletion of a precursor terpenoid which cannot be synthesized in the dark.

The group of compounds derived from fatty acids (straight-chain alcohols, alkenols, alkanals and alkenals) exhibit kinetics of formation different from those of the aforementioned terpenoids; however, individual compounds show similar kinetics. Markedly increased rates were noticed with the onset of the stationary growth phase. Polyunsaturated fatty acids present in all strains of Anabaena (Kenyon et al., 1972) including A. cylindrica (Nichols \& Wood, 1968) can be regarded as precursors of these components. The action of lipoxygenase (Galliard \& Metthew, 1977) together with a hydroperoxide lyase (Heimann et al., 1975; Vick \& Zimmermann, 1976; Hatanaka et al., 1979) on linoleic acid results in the generation of hexanal, as has been demonstrated in higher plants. The enzymic reactions which would generate the $\mathrm{C}_{5}$ compounds are less well investigated. However, $\alpha$-linoleic acid, present in high amounts in Anabaena (Kenyon et al., 1972), can be assumed to be the precursor.

The only sulphur-containing component present was dimethyldisulphide, which has previously been detected in cyanobacteria (Bechard \& Rayburn, 1979). The quantities produced, however, were too low to follow its formation during growth.

The ecological significance of the excretion of substantial amounts of volatile compounds into the environment can only be guessed at. Inhibiting effects of nor-carotenoids on the uptake and respiration of glucose were observed with aquatic heterotrophic bacteria (Reichardt, 1981). $\beta$ Ionone was demonstrated to inhibit the growth of the chlorophyte Nannochloris though the site of inhibition is not known (Jüttner, 1979). The physiological effects of mesityloxide and dimethylallylic alcohol, each reaching concentrations as high as 0.25 p.p.m. in the medium, have not yet been studied intensively.

We are greatly indebted to $\mathbf{K}$. Wurster for excellent technical assistance and $\mathbf{G}$. J. Nicholson, Institut für Organische Chemie, Tübingen University, for running the mass spectra. This work was supported by the Deutsche Forschungsgemeinschaft.

\section{REFERENCES}

BechaRd, M. J. \& RAYbuRn, W. R. (1979). Volatile organic sulfides from freshwater algae. Journal of Phycology 15, 379-383.

Galliard, T. \& Metthew, J. A. (1977). Lipoxygenase-mediated cleavage of fatty acids to carbonyl fragments in tomato fruits. Phytochemistry 16, 339. 343.

Gerber, N. N. (1968). Geosmin, from microorganisms, is trans-1,10-dimethyl-trans-9-decalol. Tetrahedron Letters, 2971-2974.

Hatanaka, A., Kajiwara, T., Sekiya, J. \& Fujimura, K. (1979). Participation of 13-hydroperoxide in the formation of $\mathrm{n}$-hexanal from linoleic acid in tea chloroplasts. Agricultural and Biological Chemistry 43, $175-176$.

Heimann, W., Franzen, K. H., Rapp, A. \&
UlLEMEYER, H. (1975). Radiogaschromatographische Analyse flüchtiger Aldehyde, die bei der mit Soja- und Hafer-Lipoxygenase katalysierten Linolsäure-Oxidation entstehen. Zeitschrift für Lebensmitteluntersuchung und -forschung 159, $1-5$.

Hertsberg, S., LiaAen-Jensen, S. \& Siegelman, H. W. (1971). The carotenoids of blue-green algae. Phytochemistry 10, 3121-3127.

JÜTTNER, F. (1979). Nor-carotenoids as the major volatile excretion products of Cyanidium. Zeitschrift für Naturforschung C 34, 186-191.

JÜTTNER, F. (1981a). Biologically active compounds released during algal blooms. Verhandlungen der Internationalen Vereinigung für theoretische und angewandte Limnologie 21, 227-230. 
JÜTTNER, F. (1981 $b$ ). Detection of lipid degradation products in the water of a reservoir during a bloom of Synura uvella. Applied and Environmental Microbio$\log y$ 41, 100-106.

JÜTTNER, F. \& HAHNE, B. (1981). Volatile excretion products of Poterioochromonas malhamensis. Identification and formation. Zeitschrift für Pflanzenphysiologie 103, 403-412.

JÜTTNER, F. \& WURSTER, K. (1979). Einfache Anordnung zur Adsorption von Geruchsstoffen aus Algen an Tenax GC und deren Überführung in Gaschromatographie-Systeme. Journal of Chromatography 175, 178-182.

KenYoN, C. N., RiPPKA, R. \& STANIER, R. Y. (1972). Fatty acid composition and physiological properties of some filamentous blue-green algae. Archiv für Mikrobiologie 83, 216-236.

Kikuchi, T., Mimura, T., Hariyama, K., Yano, H., Arimoto, T., Masada, Y. \& Inoue, T. (1973). Odorous metabolite of blue-green alga: Schizothrix muelleri NÄGELI collected in the southern basin of Lake Biwa. Identification of geosmin. Chemical and Pharmaceutical Bulletin 21, 2342-2343.

LEVIN, E. Y. \& BLOCH, K. (1964). Absence of sterols in blue-green algae. Nature, London 202, 90-91.

NADAL, N. G. M. (1971). Sterols in Spirulina maxima. Phytochemistry 10, 2537-2538.

Nichols, B. W. \& Wood, B. J. B. (1968). The occurrence and biosynthesis of gamma-linolenic acid in a blue-green alga, Spirulina platensis. Lipids $\mathbf{3}$, 46-50.

Persson, P. E. (1979). The source of muddy odor in bream (Abramis brama) from the Porvoo Sea Area (Gulf of Finland). Journal of the Fisheries Research Board of Canada 36, 883-890.

Persson, P. E. (1980). Sensory properties and analysis of two muddy odour compounds, geosmin and 2- methylisoborneol, in water and fish. Water Research 14, 1113-1118.

REICHARDT, W. (1981). Influence of methylheptenone and related phytoplankton norcarotenoids on heterotrophic aquatic bacteria. Canadian Journal of Microbiology 27, 144-147.

ReITZ, R. C. \& HAMil ton, J. G. (1968). The isolation and identification of two sterols from two species of blue-green algae. Comparative Biochemistry and Physiology 25, 401-416.

Safferman, R. S., Rosen, A. A., Mashini, C. I. \& MORRIS, M. E. (1967). Earthy-smelling substance from a blue-green alga. Environmental Science and Technology 1, 429-430.

SEely, G. R. \& JeNSEN, R. G. (1965). Effect of solvent on the spectrum of chlorophyll. Spectrochimica acta 21, 1835-1845.

StEvens, M. A. (1970). Relationship between polyenecarotene content and volatile compound composition of tomatoes. Journal of the American Society for Horticultural Science 95, 461-464.

SigwORTH, E. A. (1957). Control of odor and taste in water supplies. Journal of the American Water Works Association 49, 1507-1521.

Stransky, H. \& Hager, A. (1970). Das Carotinoidmuster und die Verbreitung des lichtinduzierten Xanthophyllcyclus in verschiedenen Algenklassen. IV. Cyanophyceae und Rhodophyceae. Archiv für Mikrobiologie 72, 84-96.

TABACHEK, J. A. L. \& YuRKowsKi, M. (1976). Isolation and identification of blue-green algae producing muddy odor metabolites, geosmin, and 2-methylisoborneol, in saline lakes in Manitoba. Journal of the Fisheries Research Board of Canada 33, 25-35.

VICK, B. A. \& ZiMmERMAN, D. C. (1976). Lipoxygenase and hydroperoxide lyase in germinating watermelon seedlings. Plant Physiology 57, 780-788. 